\title{
Tumor cells with low proteasome subunit expression predict overall survival in head and neck cancer patients
}

\author{
Chann Lagadec ${ }^{1 \dagger}$, Erina Vlashi ${ }^{1 \dagger}$, Sunita Bhuta ${ }^{2}$, Chi Lai $^{2}$, Paul Mischel ${ }^{3}$, Martin Werner ${ }^{4}$, Michael Henke ${ }^{5}$ \\ and Frank Pajonk ${ }^{1,6^{*}}$
}

\begin{abstract}
Background: Experimental and clinical data suggest that solid cancers contain treatment-resistant cancer stem cells that will impair treatment efficacy. The objective of this study was to investigate if head and neck squamous cell carcinoma (HNSCC) also contain cancer stem cells that can be identified by low 265 proteasome activity and if their presence correlates to clinical outcome.

Methods: Human HNSCC cells, engineered to report lack of proteasome activity based on accumulation of a fluorescent fusion protein, were separated based on high (ZsGreen-CODC ${ }^{\text {eg }}$ ) or low (ZsGreen-cODC ${ }^{\text {pos }}$ ) proteasome activity. Self-renewal capacity, tumorigenicity and radioresistance were assessed. Proteasome subunit expression was analyzed in tissue microarrays and correlated to survival and locoregional cancer control of 174 patients with HNSCC.

Results: HNSCC cells with low proteasome activity showed a significantly higher self-renewal capacity and increased tumorigenicity. Irradiation enriched for ZsGreen-CODC ${ }^{\text {pos }}$ cells. The survival probability of 82 patients treated with definitive radio- or chemo-radiotherapy exhibiting weak, intermediate, or strong proteasome subunit expression were $21.2,28.8$ and 43.8 months $(p=0.05)$, respectively. Locoregional cancer control was comparably affected.

Conclusions: Subpopulations of HNSCC display stem cell features that affect patients' tumor control and survival. Evaluating cancer tissue for expression of the proteasome subunit PSMD1 may help identify patients at risk for relapse.

Keywords: Cancer stem cells, Head and neck cancer, Proteasome, Radiotherapy
\end{abstract}

\section{Background}

Radiotherapy is standard of care for advanced stage head and neck squamous cell carcinoma (HNSCC). However, despite high total radiation doses combined with aggressive chemotherapy the prognosis of these patients remains poor.

First introduced a century ago by Paget [1] the cancer stem cell hypothesis suggests that, similar to leukemia, solid cancers are organized hierarchically with a small number of cancer stem cells (CSCs) able to regrow a cancer and give rise to heterogeneous progeny, which lack

\footnotetext{
* Correspondence: fpajonk@mednet.ucla.edu

${ }^{\dagger}$ Equal contributors

'Department of Radiation Oncology, David Geffen School of Medicine at UCLA, 10833 Le Conte Ave, Los Angeles, CA 90095, USA

${ }^{6}$ Jonsson Comprehensive Cancer Center at UCLA, 10833 Le Conte Ave, Los Angeles, CA 90095, USA

Full list of author information is available at the end of the article
}

these cancer stem cell traits [2]. Therefore, elimination of all CSCs from a tumor is a sine qua non for cancer cure. After a landmark paper by Al-Hajj and colleagues [3] that reported prospective identification of breast cancer stem cells, several follow-up studies provided strong clinical [4-6] and preclinical [7-10] evidence for the existence and relevance of cancer stem cells in breast cancer and glioma. The cancer stem cell hypothesis received further strong support from elegant animal experiments demonstrating the existence of cancer stem cells in undisturbed murine tumors of the GI system [11], brain [12] and skin [13]. We and others have reported that CSCs are in general resistant to established chemotherapeutic agents and are relatively radioresistant [14-18]. Thus, established treatment regimens should be re-evaluated based on their ability to kill CSCs. However, a prerequisite for such testing is the ability to identify CSCs. 
Markers for the prospective identification of CSCs are relatively well defined for breast cancer [3,19-21] and glioma $[7,9,10,21]$ while CSC markers for other solid cancers are still subject of ongoing research. A previous study suggested that CSCs in HNSCC could be prospectively identified using antibodies against the surface marker CD44 [22]. However, because CD44 is ubiquitously expressed in various isoforms, the value of CD44 as a CSC marker is controversially discussed [23]. In combination with ALDH1 staining and use of the side population CD44 still seems to be a useful marker for the prospective identification of CSCs in HNSCC [24].

We recently reported that lack of proteasome function and subunit expression is a feature of therapy-resistant, tumorigenic cells in breast cancer and glioma [16,21,25], therefore we hypothesized that HNSCCs could contain a similar cell population.

Here we report that HNSCC cell lines, indeed, contain a small population of radioresistant cells with high selfrenewal capacity that can be prospectively identified based on their intrinsic low proteasome function. Furthermore, we demonstrate that a weak expression of the proteasome subunit PSMD1 in HNSCC cells predicts unfavorable outcome after radiotherapy.

\section{Methods}

\section{Cell culture}

Human UM-SCC4, UM-SCC6, UM-SCC12, UM-SCC$17 \mathrm{~B}, \mathrm{FaDu}$, and $\mathrm{Cal} 33$ head and neck squamous carcinoma cell lines were a kind gift of Steven Wong (Department of Hematology/Oncology at UCLA) and have been previously described elsewhere [26]. ZsGreen-cODC expressing cells were obtained as described in Vlashi et al. [21]. Briefly, cells were infected with a retroviral vector coding for a fusion protein between the fluorescent protein ZsGreen and the C-terminal degron of murine ornithine decarboxylase. The latter targets ZsGreen to ubiquitinindependent degradation by the $26 \mathrm{~S}$ proteasome, thus reporting lack of proteasome function through accumulation of ZsGreen-cODC. Infected cells were selected for five days using G418. Successful complete infection was verified using the proteasome inhibitor MG132 (Sigma, MO). All cell lines were cultured in log-growth phase in DMEM (Invitrogen, Carlsbad, CA) (supplemented with $10 \%$ fetal bovine serum and penicillin and streptomycin cocktail). All cells were grown in a humidified atmosphere at $37^{\circ} \mathrm{C}$ with $5 \% \mathrm{CO}_{2}$.

\section{Irradiation}

Cells grown as monolayer or sphere cultures were irradiated at room temperature using an experimental X-ray irradiator (Gulmay Medical Inc. Atlanta, GA) at a dose rate of $5.519 \mathrm{~Gy} / \mathrm{min}$ for the time required to apply a prescribed dose. The $\mathrm{x}$-ray beam was operated at $250 \mathrm{kV}$ and hardened using a $4 \mathrm{~mm} \mathrm{Be}$, a $3 \mathrm{~mm} \mathrm{Al}$, and a $1.5 \mathrm{~mm} \mathrm{Cu}$ filter. Corresponding controls were sham irradiated.

\section{Flow cytometry}

We had previously shown that breast cancer stem cells could be identified via their low proteasome activity $[16,21]$, which can be assessed by analyzing ZsGreencODC protein accumulation. Five days after radiation, cells were trypsinized and ZsGreen-cODC expression was assessed by flow cytometry. Cells were defined as "ZsGreen-cODC positive" if the fluorescence in the FL$1 \mathrm{H}$ channel exceeded the fluorescence level of $99.9 \%$ of the empty vector-transfected control cells.

Experiments were performed using a MACSquant Analyzer (Miltenyi Biotech, CA) and analyzed using the FloJo software package (vers. 9, Tree Star Inc., OR).

For ALDH1 staining, cells were fixed in 4\% paraformaldehyde for $20 \mathrm{~min}$ at room temperature. Nonspecific binding was blocked by incubating the fixed cells for 1 hour in PBS/1\% BSA/0.1\% Tween-20/10\% goat serum at room temperature. Cells were then incubated with a mouse anti-ALDH-1 antibody (Abcam, Cambridge, $\mathrm{MA})$ at $4^{\circ} \mathrm{C}$ overnight (1:100 dilution). After washing off the non-bound primary antibody, the cells were incubated with an anti-mouse-Cy5 secondary antibody (Abcam, Cambridge, MA) in blocking buffer for 2 hours at room temperature. Cells were then washed with PBS and analyzed on BD FACSAria.

\section{Sphere-forming assay}

To assess sphere forming capacity, cells were trypsinized and plated in sphere media (DMEM-F12, 0.4\% BSA (Sigma), $10 \mathrm{ml} / 500 \mathrm{ml} \mathrm{B27} \mathrm{(Invitrogen)} 5 \mu \mathrm{g} / \mathrm{ml}$ bovine insulin (Sigma), $4 \mu \mathrm{g} / \mathrm{ml}$ heparin (Sigma), $20 \mathrm{ng} / \mathrm{ml}$ fibroblast growth factor 2 (bFGF, Sigma) and $20 \mathrm{ng} / \mathrm{ml}$ epidermal growth factor (EGF, Sigma)) into 96-well ultra-low adhesion plates, ranging from 1 to 256 cells/ well. Growth factors, EGF and bFGF, were added every 3 days, and the cells were allowed to form spheres for 21 days. The number of spheres formed per well was then counted and expressed as a percentage of the initial number of cells plated. Three independent experiments were performed.

\section{Animals}

Nude (nu/nu), 6-8-week-old female mice, originally obtained from The Jackson Laboratories (Bar Harbor, ME) were re-derived, bred and maintained in a pathogen-free environment in the American Association of Laboratory Animal Care-accredited Animal Facilities of Department of Radiation Oncology, University of California (Los Angeles, CA) in accordance to all local and national guidelines for the care of animals. 


\section{Tumor xenotransplantation}

UM-SCC12-ZsGreen-cODC-negative, derived from monolayer cultures, and UM-SCC12-ZsGreen-cODC-positive cells derived from sphere cultures and sorted by fluorescence-activated cell sorting, were injected subcutaneously into the thighs and shoulders of 6-week old female $\mathrm{Nu} / \mathrm{Nu}$ mice $\left(10^{5}, 10^{4}, 10^{3}\right.$, or $10^{2}$ cells per inoculum) within Matrigel (BD Biosciences). Tumor growth was assessed on a weekly basis, and the mice were sacrificed when the tumor size reached tumor diameters requiring euthanasia.

\section{Patients}

Records and formalin fixed tissue blocks from patients with HNSCC irradiated between January 1997 and November 2002 were evaluated within prospective clinical trials [27-30] at the University Hospital Freiburg, Germany (Table 1). Patients were originally selected to investigate the prognostic significance of blood hemoglobin levels and cellular EpoR-expression on clinical outcome. This report will focus on data of 82 patients who received definitive radiotherapy $[27,28]$ or radiochemotherapy [29,30] alone. Patients were older than 18 years and had histologically proven advanced (T3, T4, or nodal involvement) squamous-cell carcinoma of the oral cavity, oropharynx, hypopharynx, or larynx. For comparison, data from 92 additional patients with advanced HNSCC but receiving postoperative radiation within three of the above mentioned trials $[27,29,30]$ will be given in Table 2 .

All trials were approved by the ethic committee of the University Hospital, Freiburg, Germany and done in accordance with the revised Declaration of Helsinki and good clinical practice guidelines. All patients provided written informed consent. The present study was additionally approved by the institutional review board of the University Hospital, Freiburg, Germany and the University of California, Los Angeles, USA.

Conventional or three-dimensional planning techniques were used for radiotherapy. The planning target volume (PTV) included the gross tumor volume (GTV) or tumor bed with a $1-2 \mathrm{~cm}$ safety margin and the regional lymph-node areas. 6 mega electron volt linear accelerators were used and standard dose and fractionation protocols (five fractions of 2.0 Gy or 1.8 Gy per week) were followed. A total dose of 60 Gy (allowable range 56$64 \mathrm{~Gy}$ ) was prescribed to regions for R0 or R1 resected disease, and 70 Gy (allowable range 66-74 Gy) for primary definitive treatment or to macroscopically incompletely resected tumor (R2) and/or lymph nodes exceeding $2 \mathrm{~cm}$. 50 Gy were administered to uninvolved nodal regions. The spinal cord was shielded after 30-36 Gy.

Follow-up was performed quarterly for the first two years, every six months for up to five years and
Table 1 HNSCC, definitive radio- radiochemotherapy by

\section{PSMD1-score}

\begin{tabular}{lccc}
\hline PSMD1-score & $\mathbf{1}(\mathbf{n}=\mathbf{2 9})$ & $\mathbf{2}(\mathbf{n}=\mathbf{2 6})$ & $\mathbf{3}(\mathbf{n}=\mathbf{2 7})$ \\
\hline Age (years) mean & 59.5 & 62.1 & 59.3 \\
Q1/Q2/Q3 & $54 / 59 / 65$ & $56 / 61.5 / 69.7$ & $55 / 60 / 63$ \\
Male (\%) & 96.5 & 84.6 & 92.5 \\
Weight (kg) mean & 72.7 & 72.0 & 71.7 \\
Q1/Q2/Q3 & $60 / 67 / 81$ & $61.5 / 66 / 79$ & $64.5 / 72 / 80$ \\
Smoker (n) & $17 / 26$ & $19 / 24$ & $20 / 26$ \\
Karnofski >= 70 (n) & $11 / 13$ & $8 / 8$ & $6 / 7$ \\
Hemoglobin level & 12.7 & 13.5 & 13.2 \\
(mg/dL) mean & & &
\end{tabular}

\begin{tabular}{|c|c|c|c|}
\hline Q1/Q2/Q3 & $11.9 / 12.9 / 14$ & $12.8 / 13.7 / 14.1$ & $12.4 / 13.5 / 14.4$ \\
\hline Oral cavity n (\%) & $4(13.7)$ & $3(11.5)$ & $5(18.5)$ \\
\hline Oropharynx n (\%) & $13(44.8)$ & $9(34.5)$ & $9(33.3)$ \\
\hline Hypopharynx n (\%) & $10(34.4)$ & $11(42.2)$ & $8(29.6)$ \\
\hline Larynx n (\%) & $2(6.8)$ & $3(11.5)$ & $5(18.5)$ \\
\hline CT1 n (\%) & $1(3.4)$ & $1(3.8)$ & \\
\hline CT2 n (\%) & $2(6.8)$ & $3(11.5)$ & $4(14.8)$ \\
\hline cT3 n (\%) & $11(37.9)$ & $6(23.0)$ & $7(25.9)$ \\
\hline CT4 n (\%) & $15(51.7)$ & $16(61.5)$ & $16(59.2)$ \\
\hline cNO n (\%) & $2(6.8)$ & $4(15.3)$ & $3(11.1)$ \\
\hline cN1 n (\%) & $6(20.6)$ & $1(3.8)$ & $1(3.7)$ \\
\hline cN2 n (\%) & $19(65.3)$ & $20(76.8)$ & $21(57.7)$ \\
\hline cN3 n (\%) & $2(6.9)$ & $1(3.8)$ & $2(7.4)$ \\
\hline G1 n (\%) & $2(6.8)$ & $2(7.6)$ & \\
\hline G2 n (\%) & $12(41.3)$ & $17(65.3)$ & $14(53.8)$ \\
\hline G3 n (\%) & $15(51.7)$ & $7(26.9)$ & $12(46.1)$ \\
\hline EpoR (C20+) (\%) & $19(65.5)$ & $18(69.2)$ & $22(81.4)$ \\
\hline RT (Gy) mean & 71.1 & 69.7 & 67.7 \\
\hline Q1/Q2/Q3 & 70/70.6/72 & 69.9/70/70.6 & 70/70/70.6 \\
\hline RT (days) & 48.1 & 47.5 & 45.0 \\
\hline Q1/Q2/Q3 & $42.5 / 48 / 52$ & $42 / 45.5 / 51$ & $42 / 45 / 50$ \\
\hline $\begin{array}{l}\text { treated in study } \\
\text { A1/B2/C3/D4 (n) }\end{array}$ & $1 / 10 / 14 / 4$ & $3 / 10 / 7 / 6$ & $4 / 13 / 6 / 4$ \\
\hline $\begin{array}{l}\text { Local control } \\
\text { (months) median }\end{array}$ & 18.3 & $\mathrm{nr}$ & $\mathrm{nr}$ \\
\hline $\begin{array}{l}\text { Survival (months) } \\
\text { median; } 95 \% \mathrm{Cl}\end{array}$ & $21.2 ; 10.5-28.7$ & $28.8 ; 6.3-42.4$ & $43.8 ; 12.4-$ \\
\hline
\end{tabular}

continuously thereafter on a yearly basis. Locoregional tumor control and survival was assessed.

\section{Tissue microarrays}

Tissue microarrays (TMAs) and immune-histochemical staining were used to analyze the expression of the proteasome subunit PSMD1 as previously described [21,25]. Briefly, TMA enables tumor tissue samples from different 
Table 2 HNSCC, postoperative radio- radiochemotherapy by PSMD1-score

\begin{tabular}{|c|c|c|c|}
\hline PSMD1-score & $1(n=26)$ & $2(n=27)$ & $3(n=39)$ \\
\hline Age (years) mean & 63.4 & 60.8 & 60.2 \\
\hline Q1/Q2/Q3 & $58.5 / 64 / 70.2$ & $52 / 60 / 70$ & $51 / 61 / 68$ \\
\hline Male (\%) & 88.4 & 81.4 & 73.6 \\
\hline Weight $(\mathrm{kg})$ mean & 64.9 & 68.8 & 67.7 \\
\hline Q1/Q2/Q3 & $57.8 / 64.5 / 73$ & $56.8 / 68.8 / 77.5$ & $57.8 / 68.7 / 77.6$ \\
\hline Smoker (n) & $7 / 26$ & $17 / 26$ & $17 / 39$ \\
\hline $\begin{array}{l}\text { Karnofski >= } \\
70 \%(n)\end{array}$ & 19/19 & $19 / 20$ & $30 / 30$ \\
\hline $\begin{array}{l}\text { Hemoglobin level } \\
(\mathrm{mg} / \mathrm{dL}) \text { mean }\end{array}$ & 12.7 & 12.7 & 12.0 \\
\hline Q1/Q2/Q3 & 12.0/12.6/13.6 & $11.1 / 13.1 / 14$ & 11.2/11.9/12.9 \\
\hline Unknown primary & & $1(3.7)$ & \\
\hline Oral cavity n (\%) & $7(26.9)$ & $8(29.6)$ & $9(23.0)$ \\
\hline Oropharynx n (\%) & $9(34.6)$ & $10(37.0)$ & $16(41.0)$ \\
\hline $\begin{array}{l}\text { Hypopharynx } \\
\text { n (\%) }\end{array}$ & $5(19.2)$ & $2(7.4)$ & $8(20.5)$ \\
\hline Larynx n (\%) & $5(19.2)$ & $6(22.2)$ & $6(15.3)$ \\
\hline cT0 n (\%) & & $1(3.8)$ & $3(7.6)$ \\
\hline CT1 n (\%) & $7(26.9)$ & $2(7.6)$ & $7(17.9)$ \\
\hline CT2 n (\%) & $8(30.7)$ & $8(30.7)$ & $11(28.2)$ \\
\hline CT3 n (\%) & $6(23.0)$ & $6(23.0)$ & $11(28.2)$ \\
\hline cT4 n (\%) & $5(19.2)$ & $9(34.6)$ & $7(17.9)$ \\
\hline cNO n (\%) & $2(7.6)$ & $6(22.2)$ & $5(12.8)$ \\
\hline cN1 n (\%) & $5(19.2)$ & $4(14.8)$ & $14(35.8)$ \\
\hline cN2 n (\%) & $18(69.2)$ & $14(51.8)$ & 19 (48.6) \\
\hline cN3 n (\%) & $1(3.8)$ & $3(11.1)$ & $1(2.5)$ \\
\hline G1 n (\%) & & $1(3.7)$ & $1(2.5)$ \\
\hline G2 n (\%) & $12(46.1)$ & $15(55.5)$ & $21(53.8)$ \\
\hline G3 n (\%) & $14(53.8)$ & $11(40.7)$ & $17(43.5)$ \\
\hline EpoR (C20+) (\%) & $17(65.3)$ & $24(88.8)$ & $26(66.6)$ \\
\hline RT (Gy) mean & 62.9 & 63.9 & 62.2 \\
\hline Q1/Q2/Q3 & $60 / 64 / 64$ & $63 / 64 / 66$ & $60 / 63 / 64$ \\
\hline RT (days) & 46.9 & 46.3 & 45.7 \\
\hline Q1/Q2/Q3 & $43 / 45 / 48$ & $44 / 45 / 50$ & $43.7 / 44.5 / 47.5$ \\
\hline $\begin{array}{l}\text { Treated in study } \\
\text { A1/C3/D4 (n) }\end{array}$ & $3 / 22 / 1$ & $6 / 18 / 3$ & $4 / 31 / 4$ \\
\hline $\begin{array}{l}\text { Local control } \\
\text { (months) median }\end{array}$ & $\mathrm{nr}$ & $\mathrm{nr}$ & $\mathrm{nr}$ \\
\hline $\begin{array}{l}\text { Survival (months) } \\
\text { median; } 95 \% \mathrm{Cl}\end{array}$ & $48.2 ; 12.4-92.6$ & $29.3 ; 13-74.1$ & $42.8 ; 20.7-66.2$ \\
\hline
\end{tabular}

patients to be analyzed on the same histologic slide. A 2$\mathrm{mm}$ needle was used to construct the array by extracting representative tumor tissue cores from each formalinfixed, paraffin-embedded tissue blocks of HNSCC. TMA slides were counterstained with hematoxylin to visualize nuclei. PMSD1-expression analysis was performed by two pathologists who were unaware of the findings of the clinical data. A score of 1 was considered as 'weak expression', 2 was considered as 'intermediate expression', and a score of 3 was considered 'strong expression'.

\section{Statistics}

All experimental results are expressed as mean values. A $p$-value of $\leq 0.05$ in a Student's $t$-test was considered to indicate statistically significant differences. The test was applied to normalized data to compensate for the variance of measurements between biologically independent replicates of the same experiments. CSC frequencies and $p$ values were calculated using the Extreme Limiting Dilution Analysis (ELDA) software based on the algorithm defined by $\mathrm{Hu}$ and Smyth [31] (http://bioinf.wehi.edu. $\mathrm{au} /$ software/elda/). We confirmed that our data fits a single-hit linear model assumption by a likelihood ratio test to analyze goodness of fit.

The frequency of demographic and intervention parameters were descriptively determined in patients with different PSMD1-scores and locoregional tumor control and survival were assessed with Kaplan-Meier estimates within the different patient groups. Two-sided log-rank statistics were performed.

\section{Results}

HNSCC cells with low proteasome activity show increased self-renewal capacity

We had previously shown that breast cancer and glioma cells with low proteasome activity had a cancer stem cell phenotype, exhibiting increased self-renewal capacity and tumorigenicity [21]. Therefore we sought to explore if cells with intrinsically low proteasome activity could also be found in HNSCCs.

In order to assess proteasome activity in HNSCC lines we engineered UM-SCC4, UM-SCC6, UM-SCC12, UMSCC-17B, Cal33 and FaDu cells to report the activity of this protease by accumulation of a fusion protein between the fluorescent protein ZsGreen and the C-terminal degron of murine ornithine decarboxylase (cODC). The latter directs the fusion protein to ubiquitin-independent degradation by the $26 \mathrm{~S}$ proteasome. Therefore, cells with low proteasome activity accumulate the fluorescent fusion protein.

When cells were kept as monolayer cultures, a low number of cells accumulated the fusion protein, thus indicating the presence of a small subpopulation of cells with intrinsically low proteasome activity (Figure 1a). When the UM-SCC6-ZsGreen-cODC and UM-SCC12ZsGreen-cODC cells were grown in suspension as spheres in serum-free media supplemented with growth factors, the cultures were enriched in ZsGreen-cODC ${ }^{\text {pos }}$ 


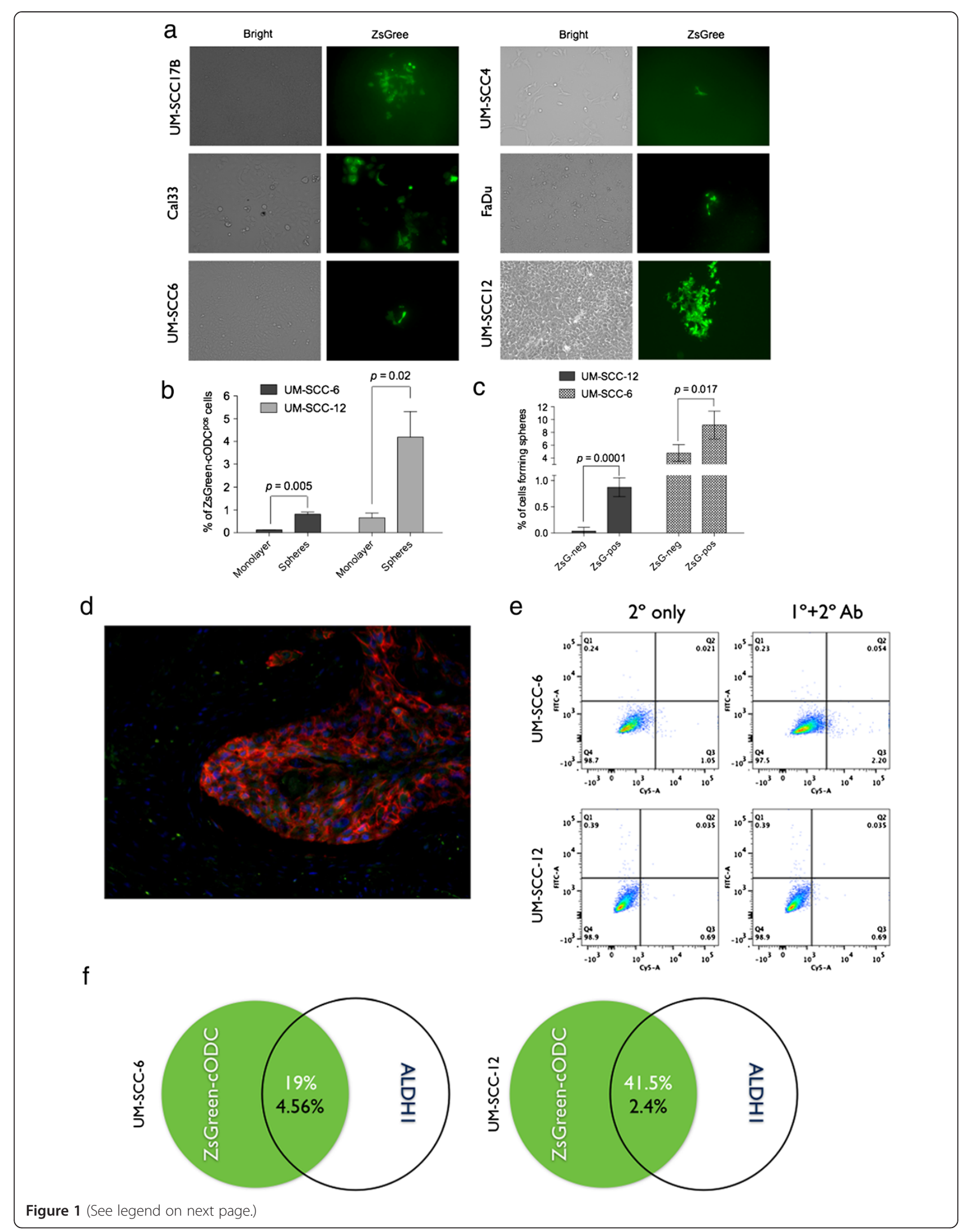


(See figure on previous page.)

Figure 1 HNSCC cell lines contain cell populations with low proteasome activity and higher sphere-forming capacity. HNSCC cell lines were engineered to express the fusion protein ZsGreen and the c-terminal of the degron ornithine decarboxylase (cODC). (a) Cell lines were cultured in log-growth phase in DMEM, and representative bright field and green fluorescent pictures of monolayer cells are shown. (b) The percentage of ZsGreen-cODC ${ }^{\text {pos }}$ cells increases when HNSCC cells are cultured in serum-free media as tumorspheres. (c) Percentage of cells forming spheres from the ZsGreen-CODC neg (ZsG-) and ZsGreen-cODC ${ }^{\text {pos }}$ (ZsG+) population after sorting by flow cytometry into 96-well plates. Means \pm SD from four independent experiments are shown. (d) Representative CD44 staining of a HNSCC patient-derived tumor sample. Tumor cells show uniform membrane staining for CD44 (red). Nuclei are counterstained with DAPI (blue). (e) and (f) Flow cytometry analysis of ZsGreen accumulation (Y-axis) and ALDH1 expression (X-axis) in UM-SCC-6 and UM-SCC-12 cells). ZsGreen-CODC ${ }^{\text {pos }}$ cells with low proteasome activity are a subpopulation of ALDH1expressing cells with 19\% of ZsGreen-CODC ${ }^{\text {pos }}$ UM-SCC-6 cells and $41.5 \%$ of UM-SCC-12 cells positive for ALDH1.

cells (\% UM-SCC6-ZsGreen-cODC ${ }^{\text {pos }}$ from monolayer: $0.12 \pm 0.008 ; \%$ UM-SCC6-ZsGreen-cODC ${ }^{\text {pos }}$ from spheres: $0.812 \pm 0.19, \quad p=0.005, \mathrm{n}=4 ; \quad(\%$ UM-SCC12-ZsGreencODC $^{\text {pos }}$ from monolayer: $0.655 \pm 0.42 ; \%$ UM-SCC12ZsGreen-cODC ${ }^{\text {pos }}$ from spheres: $5.24 \pm 0.97 ; p=0.02, \mathrm{n}=$ 4 , two-sided Student's t-test; Figure 1b). These growth conditions select for stem cells, while cells with limited proliferative potential die by anoikis. Furthermore, we sorted the UM-SCC6-ZsGreen-cODC and UM-SCC12ZsGreen-cODC cells into ZsGreen-cODC ${ }^{\text {neg }}$ (high proteasome activity) and ZsGreen-cODC ${ }^{\text {pos }}$ (low proteasome activity) via FACS, and seeded these populations of cells into ultra-low adhesion plates in an in vitro limiting dilution assay (256 to 1 cells/well) under serum-free conditions and allowed for formation of tumor spheres. The sphere-forming capacity of these two subpopulations of cells differed in the two cell lines, however the ZsGreencODC $^{\text {pos }}$ cells from both lines showed a significantly higher self-renewal capacity compared to the ZsGreencODC $^{\text {neg }}$ cells (sphere forming capacity of UM-SCC6ZsGreen-cODC ${ }^{\text {pos }} 9.15 \pm 1.26 \%$; UM-SCC6-ZsGreen-cO $\mathrm{DC}^{\text {neg }} 4.77 \pm 0.76 \% \mathrm{p}=0.041, \mathrm{n}=3$; sphere forming capacity of UM-SCC12-ZsGreen-cODC ${ }^{\text {pos }} 0.88 \pm 0.097 \%$; UM-SCC12-ZsGreen-cODC ${ }^{\text {neg }} 0.038 \pm 0.038 \% \mathrm{p}=0.0001$, $\mathrm{n}=4$, two-sided Student's t-test; Figure 1c). This data suggested that HNSCC are organized hierarchically or at least are heterogeneous with respect to their ability to self-renew.

In order to test if ZsGreen-cODC ${ }^{\text {pos }}$ cells in HNSCC overlap with cells positive for other established CSCs markers, HNSCC tumor sections were stained against CD44. CD44 caused a rather uniform membrane staining of the tumor cells (Figure 1d), which did not reflect the level of tumorigenicity seen in HNSCC xenografts studies.

The ZsGreen-cODC system cannot be used in combination with the Aldefluor assay, which uses a greenfluorescent substrate and therefore UM-SCC- 6 and UM-SCC-12 cells were stained with an antibody against ALDH1 as described previously [20]. In both cell lines ZsGreen-cODC ${ }^{\text {pos }}$ cells with low proteasome activity were a subpopulation of ALDH1-expressing cells (Figure 1e and f).

To further confirm the tumor-initiating properties of the ZsGreen-cODC-positive population of cells we assessed the tumorigenicity of ZsGreen-cODC ${ }^{\text {pos }}$ and $Z_{s G r e e n-c O D C}{ }^{\text {neg }}$ cells in vivo. When UM-SCC12cODC cells were injected into female nude mice, ZsGreen-cODC ${ }^{\text {pos }}$ showed a 20 -fold higher tumorigenicity than ZsGreen-cODC ${ }^{\text {neg }}$ cells, thus suggesting that HNSCC cells with low proteasome activity are indeed highly enriched for CSCs (Table 3). The estimated frequencies of CSCs were 1 in 175,145 (CI: 410455 $74737)$ in the ZsGreen-cODC ${ }^{\text {neg }}$ cell population and 1 in 48,942 (CI: $127,609-18,771$ ) in the ZsGreencODC ${ }^{\text {pos }}$ cell population with ZsGreen-cODC ${ }^{\text {pos }}$ cells containing significantly more CSCs ( $\mathrm{p}=0.0315$, Chi-Square test).

\section{Radiation treatment enriches for HNSCC cells with low proteasome activity}

Next, we tested if cells with intrinsically low proteasome activity would be intrinsically radioresistant. All the cell lines were seeded as monolayer cultures and treated with 5 daily fractions of 3 Gy. The number of ZsGreen$\mathrm{cODC}^{\text {pos }}$ cells was assessed 72 hours after the last fraction of radiation, thus simulating a typical week of radiation treatment followed by a weekend gap. In all cell lines, fractionated radiation caused a significant increase in the percentage of ZsGreen-cODC ${ }^{\text {pos }}$ cells, suggesting that cells with low proteasome activity are indeed intrinsically radioresistant (Figure 2a and e). When the two different growth conditions were tested (monolayer vs. sphere media) with the UM-SCC-12-ZsGreen-cODC and UM-SCC-6-ZsGreen-cODC cells, the radiation-induced increase in $\mathrm{ZsGreen-cODC}{ }^{\text {pos }}$ cells was seen regardless of the culture conditions chosen (Figure 2a and b).

Table 3 In vivo limiting dilution assay for UM-SCC12 cells

\begin{tabular}{lcc}
\hline \multicolumn{3}{c}{ UM-SCC12-ZsGreen-cODC } \\
\hline \# of cells/innoculum & ZsG $^{\text {neg }}$ & ZsG $^{\text {pos }}$ \\
\hline 100 & $0 / 10$ & $0 / 10$ \\
1,000 & $0 / 12$ & $2 / 10$ \\
10,000 & $1 / 10$ & $3 / 8$ \\
100,000 & $4 / 10$ & $2 / 4$ \\
$1,000,000$ & $4 / 4$ & Not performed
\end{tabular}




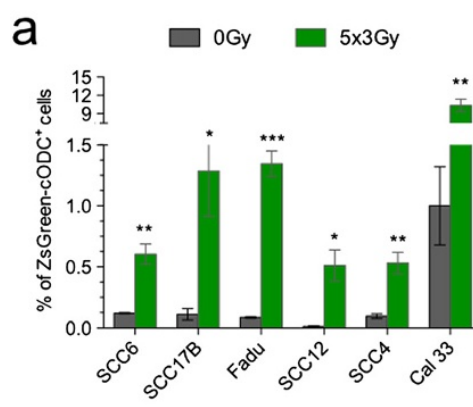

C
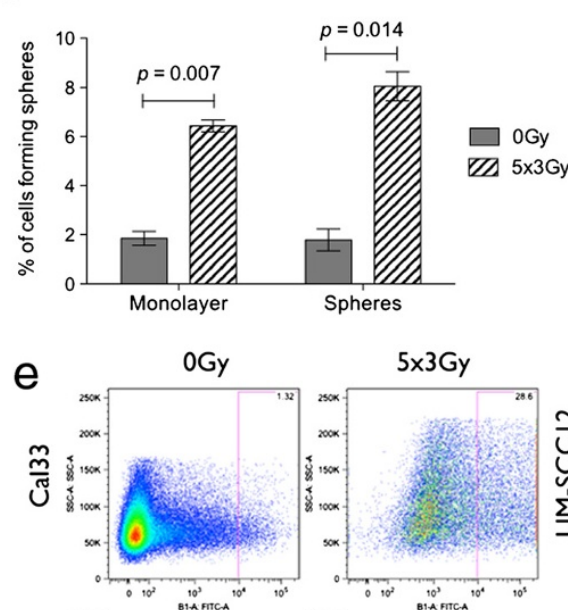

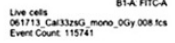

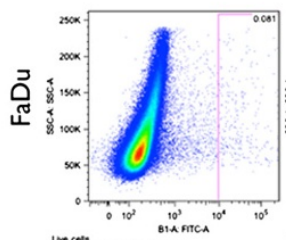

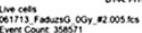

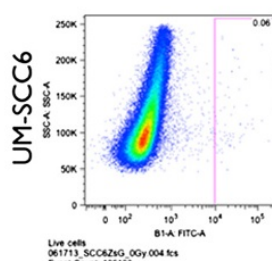

sinctists

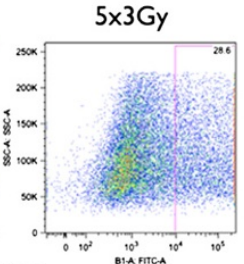

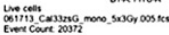

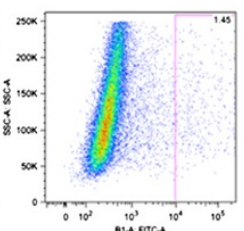

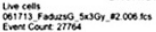

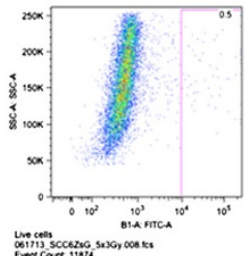

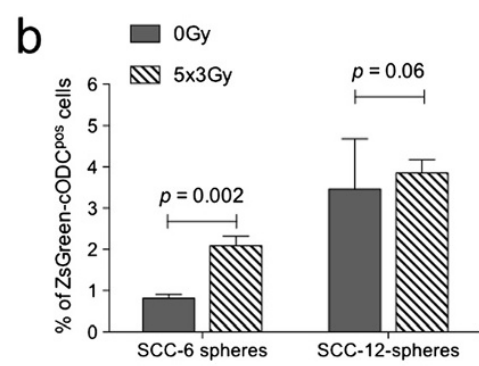

d
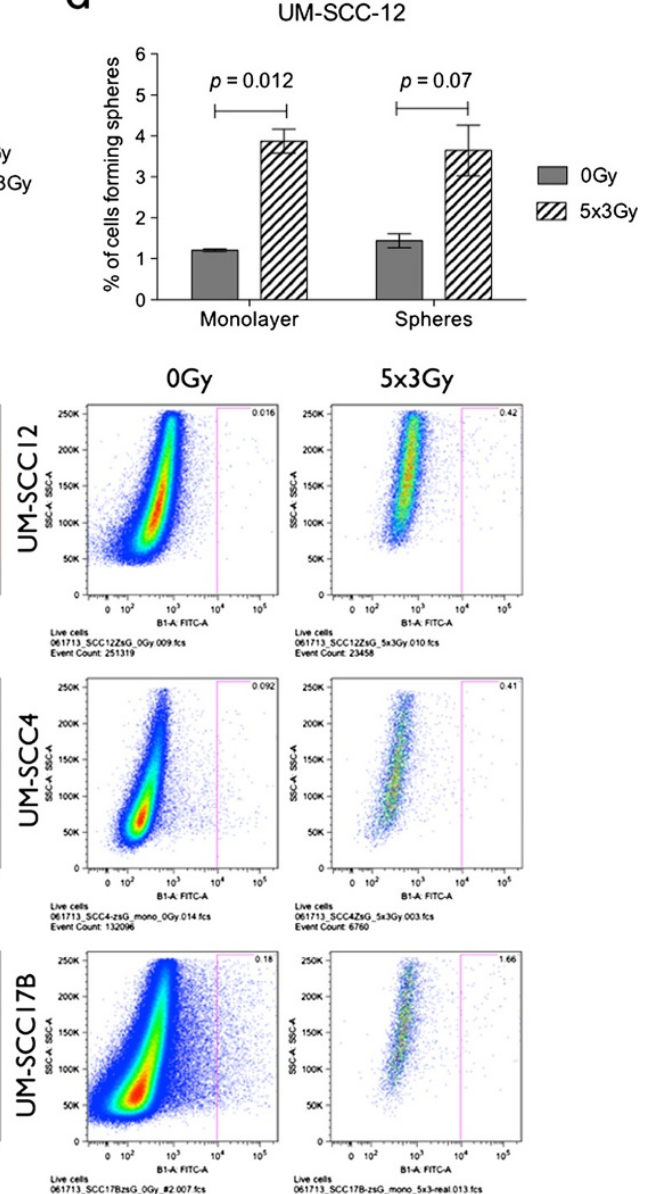

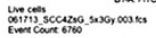

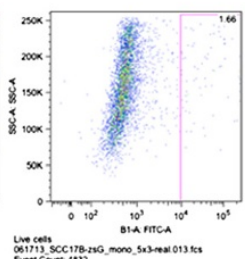

Figure 2 Radiation enriches for cells with low proteasome activity and increases self-renewal capacity. (a) HNSCC cells stably expressing the ZsGreen-CODC fusion protein were grown as monolayers cultures and treated with 5 daily fractions of $3 \mathrm{~Gy}$. The number of ZsGreen-cODC ${ }^{\text {pos }}$ cells was assessed 72 hours after the last fraction of radiation using flow cytometry. Shown are mean percentages of ZsGreen-cODC ${ }^{\text {pos }}$ cells with standard deviation (SD). (b) Treatment of UM-SCC-6-ZsGreen-CODC and UM-SCC-12-ZsGreen-CODC sphere cultures were treated with 5 fractions of $3 \mathrm{~Gy}$, also resulting in enrichment of ZsGreen-CODC ${ }^{\text {pos }}$ cells with low proteasome activity. This effect was more pronounced in radiosensitive [39] UM-SCC-6 cells than in radioresistant [40] UM-SCC12 cells. (c and d) 72 hours after the last fraction of radiation, cells were plated in 96-well plates at clonal densities to assess self-renewal capacity. Mean $( \pm$ SD) percentages of cells forming a sphere with are shown. (e) Representative FACS analysis of HNSCC cell lines (monolayer) after treatment with 0 or $5 \times 3 \mathrm{~Gy}$.

\section{Radiation increases the self-renewal capacity of} HNSCC cells

Next we assessed if radiation-induced increases in the number of ZsGreen-cODC ${ }^{\text {pos }}$ cells with low proteasome activity translated into increased self-renewal capacity. UM-SCC-6 and UM-SCC-12 were cultured as monolayers or tumorspheres and irradiated with 5 daily fractions of 3 Gy followed by a typical weekend gap of 
72 hours. At this time, cells we seeded at clonal densities into ultra-low adhesions plates in sphere media. After 15 days, tumor spheres were counted. In both cell lines, irradiation caused a significant increase in self-renewal capacity for cells cultured as monolayers or tumorspheres (Monolayers: UM-SCC6, 0 Gy: $1.85 \pm 0.28,5 \times 3$ Gy: 6.434 \pm $0.25, \mathrm{p}=0.007, \mathrm{n}=2$; UM-SCC12: 0 Gy: $1.2 \pm 0.03 \%, 5 \times 3$ Gy: $3.87 \pm 0.29 \% \mathrm{p}=0.012, \mathrm{n}=2$; Spheres: UM-SCC6, 0 Gy: $1.78 \pm 0.45 \%, 5 \times 3$ Gy: $8.05 \pm 0.59 \%, \mathrm{p}=0.014, \mathrm{n}=2$; UMSCC12, 0 Gy: $1.44 \pm 0.17,5 \times 3$ Gy: $3.65 \pm 0.62 \% p=0.075$, $\mathrm{n}=2$, two-sided Student's t-test; Figure $2 \mathrm{c}$ and $\mathrm{d}$ ).

\section{Low proteasome subunit expression in HNSCC cells predicts treatment outcome}

In order to test the clinical significance of cells with decreased proteasome activity in HNSCCs we used a tissue microarray that contained tumor samples of 82 HNSCC cases treated with primary definitive radiotherapy or radiochemotherapy. We previously described that lack of staining for the $19 \mathrm{~S}$ proteasome regulatory subunit PSMD1 correlates with lack of $26 \mathrm{~S}$ proteasome activity $[21,25]$.

Figure 3a shows representative staining for levels 1-3 and Table 1 presents clinical data of patients by PSMD1score. Characteristics of all three patient groups were quite similar. Possible imbalances in regards to tumor site, nodal involvement, erythropoietin receptor [32] or radiation may - if at all - favor patients with weak PSMD1expression scores.

Kaplan-Meier estimates show that patients who underwent radiotherapy for macroscopic tumor and whose tumor cells exhibited weak or intermediate, as opposed to strong PSMD1 expression, had a decreased median overall survival probability (21.2 vs 28.8 vs 43.8 months, log-rank, $\mathrm{p}=0.05$ ) (Figure 3b). Comparably, a trend was observed for time to local tumor progression within the irradiated volume $(\mathrm{p}=0.08$, Figure $3 \mathrm{c})$. This suggested that the number of cancer stem cells present during radiation treatment had an impact on treatment outcome.

In the case of patients in which the tumors could be resected successfully, expression of the proteasome subunit PSMD1 in cancer cells before surgery did not correlate with survival (Figure 3d). A description of these patients is given in Table 2 .

\section{Discussion}

We had previously reported that breast cancer [16] and glioma [21] cells with intrinsically low proteasome activity have a CSC phenotype. Similar results were reported for NSCLC [33] and pancreatic cancer [34]. Interestingly, in prostate cancer [35], breast cancer [16,36], and glioma [21,25] cells with low proteasome activity are radioresistant and patients with breast cancers [37] or gliomas [25] that express low levels of proteasome subunits have an unfavorable outcome. Recently, we reported that activation of the developmental Notch signaling pathway links the CSC phenotype with the proteasome. Musashi, a RNA binding protein crucial for maintaining Notch signaling, binds to the 3'-UTR of NF-YA mRNA, the master regulator of mammalian proteasome subunit expression, thereby down-regulating the proteasome in CSCs [38]. The intrinsic low proteasome activity in CSCs parallels with metabolic changes [25] and up-regulation of free radical scavenger systems, which ultimately cause radioresistance $[17,36]$.

In the present study we show that HNSCC also contains a population of cells with low proteasome activity and decreased proteasome subunit expression and that these cells have a CSC phenotype defined by operational means. Like in breast cancer [16] or glioma [21], radiation enriches for these cells by selectively killing the more radiosensitive population with high proteasome activity and lower self-renewing capacity.

To our knowledge we show here for the first time that the number of cells with low proteasome activity present in HNSCCs inversely correlates with the overall survival of patients suffering from HNSCC. It is unlikely that design, conduct or patient selection contributed to this finding. The clinical samples were derived from prospective trials where data collection, validation, and processing followed good clinical practice; the adherence to study protocols was ascertained and a continuous follow-up for nine years sufficiently substantiates our observation. Although the sample size is limited, essential methodological pitfalls seem not to confound our observations. Baseline and treatment characteristics are reasonably balanced, immune-histochemical processing is standardized by TMA-methodology, adequate controls were used, and two unbiased, independent researchers, blinded for all clinical parameters, performed the evaluation.

PSMD1 expression seemed to also affect the locoregional cancer control probability of our patients undergoing primary definitive radiotherapy and we propose that treatment outcome was predominantly driven by an impaired treatment efficacy based on an increased number of therapy resistant CSCs. Furthermore, our in vitro data suggested that radiation enriches for CSCs and increases self-renewal capacity of HNSCC cell populations. Finally, the number of CSCs in patients in which the tumor could be resected was not related to the prognosis (Table 2 and Figure 3), thus supporting the relevance of the total number of CSCs for overall survival. One can speculate that the very low number of CSCs in subclinical disease in those patients will most likely be controlled by standard radiotherapy regimens. 


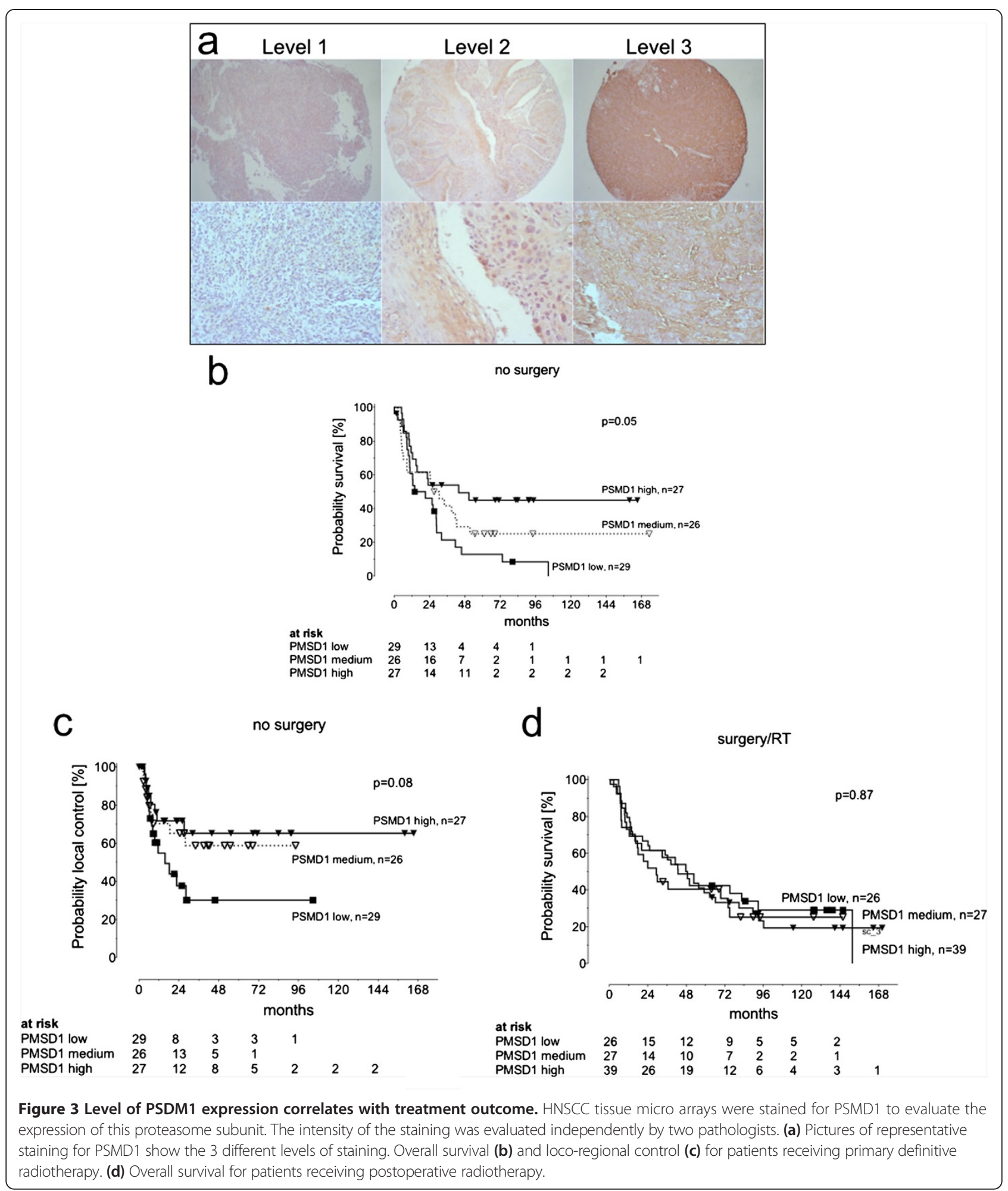

\section{Conclusions}

We conclude that HNSCCs contain subpopulations of cells with CSC features, which can be identified by lack of proteasome activity and low proteasome subunit
PSMD1-expression. HNSCC CSCs are of clinical relevance because they affect tumor control and survival. Thus, PSMD1-testing could be useful in identifying patients with HNSCC at risk for relapse. 


\section{Competing interests}

The authors have declared that no conflict of interest exists.

\section{Authors' contributions}

$\mathrm{CL}$ performed the in vitro and in vivo experiments, EV performed the in vitro and in vivo experiments and wrote the manuscript, SB and CL scored the tissue micro arrays, PM and MW were responsible for the TMA assembly and staining, $\mathrm{MH}$ collected and analyzed the clinical data, FP conceived of the study, designed the experiments, analyzed the data and wrote the manuscript. All authors read and approved the final version of the manuscript.

\section{Acknowledgements}

This work was supported by a generous gift from Steve and Cathy Fink and grants from the National Cancer Institute (1RO1CA137110, 1R01CA161294) and the Army Medical Research \& Materiel Command's Breast Cancer Research Program (W81XWH-11-1-0531) to FP.

\section{Author details}

'Department of Radiation Oncology, David Geffen School of Medicine at UCLA, 10833 Le Conte Ave, Los Angeles, CA 90095, USA. ²Department of Pathology, David Geffen School of Medicine at UCLA, 10833 Le Conte Ave, Los Angeles, CA 90095, USA. ${ }^{3}$ Ludwig Institute for Cancer Research, San Diego Branch, 9500 Gilman Drive, La Jolla, CA 92039, USA. ${ }^{4}$ Department of Pathology, University Hospital Freiburg, Breisacher Str. 115a, 79106 Freiburg, Germany. ${ }^{5}$ Section Clinical Studies, Department of Radiation Oncology, University Hospital Freiburg, Robert-Koch-Strasse 3, D-79106 Freiburg, Germany. ${ }^{6}$ Jonsson Comprehensive Cancer Center at UCLA, 10833 Le Conte Ave, Los Angeles, CA 90095, USA.

Received: 6 September 2013 Accepted: 24 February 2014 Published: 5 March 2014

\section{References}

1. Paget S: The distribution of secondary growths in cancer of the breast. Lancet 1889, 1:571-573.

2. Reya T, Morrison SJ, Clarke MF, Weissman IL: Stem cells, cancer, and cancer stem cells. Nature 2001, 414:105-111.

3. Al-Hajj M, Wicha MS, Benito-Hernandez A, Morrison SJ, Clarke MF: Prospective identification of tumorigenic breast cancer cells. Proc. Natl Acad. Sci. USA 2003, 100:3983-3988

4. Charafe-Jauffret E, Ginestier C, lovino F, Tarpin C, Diebel M, Esterni B, Houvenaeghel G, Extra JM, Bertucci F, Jacquemier J, Xerri L, Dontu G, Stassi G, Xiao Y, Barsky SH, Birnbaum D, Viens P, Wicha MS: Aldehyde dehydrogenase 1-positive cancer stem cells mediate metastasis and poor clinical outcome in inflammatory breast cancer. Clin Cancer Res 2010, 16:45-55.

5. Pallini R, Ricci-Vitiani L, Banna GL, Signore M, Lombardi D, Todaro M, Stassi G, Martini M, Maira G, Larocca LM, De Maria R: Cancer stem cell analysis and clinical outcome in patients with glioblastoma multiforme. Clin Cancer Res 2008, 14:8205-8212.

6. Zeppernick F, Ahmadi R, Campos B, Dictus C, Helmke BM, Becker N, Lichter P, Unterberg A, Radlwimmer B, Herold-Mende CC: Stem cell marker CD133 affects clinical outcome in glioma patients. Clin Cancer Res 2008, 14:123-129.

7. Hemmati HD, Nakano I, Lazareff JA, Masterman-Smith M, Geschwind DH, Bronner-Fraser M, Kornblum HI: Cancerous stem cells can arise from pediatric brain tumors. Proc Natl Acad Sci U S A 2003, 100:15178-15183.

8. Schatton T, Murphy GF, Frank NY, Yamaura K, Waaga-Gasser AM, Gasser M, Zhan Q, Jordan S, Duncan LM, Weishaupt C, Fuhlbrigge RC, Kupper TS, Sayegh $\mathrm{MH}$, Frank MH: Identification of cells initiating human melanomas. Nature 2008, 451:345-349.

9. Singh SK, Clarke ID, Terasaki M, Bonn VE, Hawkins C, Squire J, Dirks PB: Identification of a cancer stem cell in human brain tumors. Cancer Res 2003, 63:5821-5828.

10. Singh SK, Hawkins C, Clarke ID, Squire JA, Bayani J, Hide T, Henkelman RM, Cusimano MD, Dirks PB: Identification of human brain tumour initiating cells. Nature 2004, 432:396-401.

11. Schepers AG, Snippert HJ, Stange DE, van den Born M, van Es JH, van de Wetering $\mathrm{M}$, Clevers $\mathrm{H}$ : Lineage tracing reveals Lgr5+ stem cell activity in mouse intestinal adenomas. Science 2012, 337:730-735.
12. Chen J, Li Y, Yu TS, McKay RM, Burns DK, Kernie SG, Parada LF: A restricted cell population propagates glioblastoma growth after chemotherapy. Nature 2012, 488:522-526. \#3427400.

13. Driessens G, Beck B, Caauwe A, Simons BD, Blanpain C: Defining the mode of tumour growth by clonal analysis. Nature 2012, 488:527-530.

14. Bao S: Glioma stem cells promote radioresistance by preferential activation of the DNA damage response. Nature 2006, 444:756-760.

15. Eramo A, Ricci-Vitiani $L$, Zeuner A, Pallini R, Lotti F, Sette G, Pilozzi E, Larocca LM, Peschle C, De Maria R: Chemotherapy resistance of glioblastoma stem cells. Cell Death Differ 2006, 13:1238-1241.

16. Lagadec C, Vlashi E, Della Donna L, Meng Y, Dekmezian C, Kim K, Pajonk F: Survival and self-renewing capacity of breast cancer initiating cells during fractionated radiation treatment. Breast Cancer Res 2010, 12:R13.

17. Phillips TM, McBride WH, Pajonk F: The response of CD24(-/low)/CD44+ breast cancer-initiating cells to radiation. J Natl Cancer Inst 2006, 98:1777-1785.

18. Woodward WA, Chen MS, Behbod F, Alfaro MP, Buchholz TA, Rosen JM: WNT/beta-catenin mediates radiation resistance of mouse mammary progenitor cells. Proc Natl Acad Sci U S A 2007, 104:618-623.

19. Fillmore CM, Kuperwasser C: Human breast cancer cell lines contain stemlike cells that self-renew, give rise to phenotypically diverse progeny and survive chemotherapy. Breast Cancer Res 2008, 10:R25

20. Ginestier C, Hur MH, Charafe-Jauffret E, Monville F, Dutcher J, Brown M, Jacquemier J, Viens P, Kleer CG, Liu S, Schott A, Hayes D, Birnbaum D, Wicha MS, Dontu G: ALDH1 Is a marker of normal and malignant human mammary stem cells and a predictor of poor clinical outcome. Cell Stem Cell 2007, 1:555-567.

21. Vlashi E, Kim K, Lagadec C, Donna LD, McDonald JT, Eghbali M, Sayre JW Stefani E, McBride W, Pajonk F: In vivo imaging, tracking, and targeting of cancer stem cells. J Natl Cancer Inst 2009, 101:350-359.

22. Prince ME: Identification of a subpopulation of cells with cancer stem cell properties in head and neck squamous cell carcinoma. Proc. Natl Acad. Sci. USA 2007, 104:973-978.

23. Zoller M: CD44: can a cancer-initiating cell profit from an abundantly expressed molecule? Nat Rev Cancer 2011, 11:254-267.

24. Bertrand G, Maalouf M, Boivin A, Battiston-Montagne P, Beuve M, Levy A Jalade P, Fournier C, Ardail D, Magne N, Alphonse G, Rodriguez-Lafrasse C: Targeting head and neck cancer stem cells to overcome resistance to photon and carbon ion radiation. Stem Cell Reviews 2014, 10:114-126.

25. Vlashi E, Lagadec C, Vergnes L, Matsutani T, Masui K, Poulou M, Popescu R, Della Donna L, Evers P, Dekmezian C, Reue K, Christofk H, Mischel PS, Pajonk F: Metabolic state of glioma stem cells and nontumorigenic cells. Proc Natl Acad Sci U S A 2011, 108:16062-16067.

26. Buchhagen DL, Worsham MJ, Dyke DL, Carey TE: Two regions of homozygosity on chromosome $3 p$ in squamous cell carcinoma of the head and neck: comparison with cytogenetic analysis. Head Neck 1996, 18:529-537.

27. Brizel DM, Wasserman TH, Henke M, Strnad V, Rudat V, Monnier A, Eschwege F, Zhang J, Russell L, Oster W, Sauer R: Phase III randomized trial of amifostine as a radioprotector in head and neck cancer. J Clin Oncol 2000, 18:3339-3345.

28. Budach V, Stuschke M, Budach W, Baumann M, Geismar D, Grabenbauer G, Lammert I, Jahnke K, Stueben G, Herrmann T, Bamberg M, Wust P, Hinkelbein W, Wernecke KD: Hyperfractionated accelerated chemoradiation with concurrent fluorouracil-mitomycin is more effective than dose-escalated hyperfractionated accelerated radiation therapy alone in locally advanced head and neck cancer: final results of the radiotherapy cooperative clinical trials group of the german cancer society 95-06 prospective randomized trial. J Clin Oncol 2005, 23:1125-1135.

29. Henke M, Laszig R, Rübe C, Schäfer U, Haase KD, Schilcher B, Mose S, Beer KT, Burger U, Dougherty C, Frommhold H: Erythropoietin to treat head and neck cancer patients with anaemia undergoing radiotherapy: randomised, double-blind, placebo-controlled trial. The Lancet 2003, 262:1255-1260.

30. Trotti A, Garden A, Warde P, Symonds P, Langer C, Redman R, Pajak TF, Fleming TR, Henke M, Bourhis J, Rosenthal DI, Junor E, Cmelak A, Sheehan F, Pulliam J, Devitt-Risse P, Fuchs H, Chambers M, O'Sullivan B, Ang KK: A multinational, randomized phase III trial of iseganan $\mathrm{HCl}$ oral solution for reducing the severity of oral mucositis in patients receiving radiotherapy for head-and-neck malignancy. Int J Radiat Oncol Biol Phys 2004, 58:674-681. 
31. Hu Y, Smyth GK: ELDA: extreme limiting dilution analysis for comparing depleted and enriched populations in stem cell and other assays. $\mathrm{J}$ Immunol Methods 2009, 347:70-78.

32. Henke M, Mattern D, Pepe M, Bezay C, Weissenberger C, Werner M, Pajonk F: Do erythropoietin receptors on cancer cells explain unexpected clinical findings? J Clin Oncol 2006, 24:4708-4713.

33. Pan J, Zhang Q, Wang Y, You M: $26 \mathrm{~S}$ proteasome activity is downregulated in lung cancer stem-like cells propagated in vitro. PLoS One 2010, 5:e13298.

34. Adikrisna R, Tanaka S, Muramatsu S, Aihara A, Ban D, Ochiai T, Irie T, Kudo A, Nakamura N, Yamaoka S, Arii S: Identification of pancreatic cancer stem cells and selective toxicity of chemotherapeutic agents. Gastroenterology, 143(2012):234-245. e237.

35. Della Donna L, Lagadec C, Pajonk F: Radioresistance of prostate cancer cells with low proteasome activity. Prostate 2012, 72:868-874.

36. Lagadec C, Dekmezian C, Bauche L, Pajonk F: Oxygen levels do not determine radiation survival of breast cancer stem cells. PLoS One 2012, 7:e34545.

37. Elfadl D, Hodgkinson VC, Long ED, Scaife L, Drew PJ, Lind MJ, Cawkwell L: A pilot study to investigate the role of the $26 \mathrm{~S}$ proteasome in radiotherapy resistance and loco-regional recurrence following breast conserving therapy for early breast cancer. Breast 2011, 20:334-337.

38. Lagadec C, Vlashi E, Frohnen P, Alhiyari Y, Chan M, Pajonk F: The RNAbinding protein Musashi-1 regulates proteasome subunit expression in breast cancer- and glioma-initiating cells. Stem cells 2014, 32:135-144.

39. Bonner JA, Maihle NJ, Folven BR, Christianson TJ, Spain K: The interaction of epidermal growth factor and radiation in human head and neck squamous cell carcinoma cell lines with vastly different radiosensitivities. Int J Radiat Oncol Biol Phys 1994, 29:243-247.

40. Yang J, McEachern D, Li W, Davis MA, Li H, Morgan MA, Bai L, Sebolt JT, Sun H, Lawrence TS, Wang S, Sun Y: Radiosensitization of head and neck squamous cell carcinoma by a SMAC-mimetic compound, SM-164, requires activation of caspases. Mol Cancer Ther 2011, 10:658-669.

doi:10.1186/1471-2407-14-152

Cite this article as: Lagadec et al:: Tumor cells with low proteasome subunit expression predict overall survival in head and neck cancer patients. BMC Cancer 2014 14:152.

\section{Submit your next manuscript to BioMed Central and take full advantage of:}

- Convenient online submission

- Thorough peer review

- No space constraints or color figure charges

- Immediate publication on acceptance

- Inclusion in PubMed, CAS, Scopus and Google Scholar

- Research which is freely available for redistribution 